\title{
Making Qualitative Research Material Reusable: Case in Finland
}

The Finnish Social Science Data Archive (FSD) is a national resource centre for social science research and teaching. It started operating as a separate unit within the University of Tampere in the beginning of 1999. As in other data archives, the main task of the FSD is to increase the use of existing social science data by disseminating it. The main functions include acquiring, storing and disseminating data for secondary research. In the beginning, the FSD will concentrate on storing numerical data but in the future information services will also cover qualitative data.

This paper gives background information on the reasons why data archive information services in Finland will also cover qualitative data. To make this understandable I shall first give a short history of qualitative research methods in Finland and their position here. After that I take a look at perspectives and problems in the reuse of qualitative data in Finland. Since I am a sociologist, the focus is on social sciences and the approach is characterised by my own discipline.

\section{Qualitative social research in Finland}

In the beginning of the last century it was typical in social sciences to use many kinds of data. Official statistics, newspaper articles, and stories told by the people who were being studied as well, could form the basis of analyses. A remarkable example of combining data is one of our classic studies carried out by Heikki Waris in the 1930's. First he collected and analysed statistics and figures on living conditions of the working class in Helsinki - the capital of Finland. In the second phase of his research, he actually walked into the area inhabited by workers and observed and interviewed the people there so that he would be able to understand how these working class people really lived (Waris 1932).

This celebrated study, using both quantitative and qualitative data, did not, however, become any particular lodestar for the methodology of social sciences during the decades that followed. Taking a look at the methodological literature of the 1950's and the 1960's it is quite clear that statistical methods were in the mainstream though qualitative methods had their small share, too. For sociology's part, however, it can be claimed that almost all the traditions of qualitative research were broken during those decades (Leskinen 1995). Social scientists were fascinated by survey-methods which eventually became, at least in Finland, the scientific method in social sciences from the late 1940 's to the early 1970's.

The 1970's marked a turning point in social sciences in Finland. Survey methods were criticised for being ideologically obscure. It was claimed that using concepts like 'universe' or 'analysing unit' just brought to mind an idea of an individual as the subject of his/her actions. And that certainly was not the idea of society in the political and economic theory of Karl Marx. In the 1970's, it was Marxism that laid the foundation or canon for what constituted being a researcher in an acceptable way in Finland. In those days, Marxism marked the boundaries between theoretical research and positivism. The use of survey methods was reckoned as not being theoretical but positivist (Töttö 1997). This did not mean that survey methods would have been totally banned and vanished. The majority of empirical studies in sociology were still based on quantitative data. But they were not in the forefront. Ironically, one could say that, when writing an article in the Finnish journal Sociology after mid 1970's, you would not have put a single table in it without a careful deliberation.

The 1970's was an era of particularly philosophical and theoretical studies in social sciences. And this certainly made the gap yawn between theory and practice or the empirical world. This discrepancy was one of the main reasons for a turn towards using qualitative methods in the late 1970's (Leskinen 1995). Being extremely philosophical and theoretical, social sciences were not capable of producing any methods or instruments for empirical research. Though Marxism left its traces in the first empirical and qualitative studies in sociology, the increasing use of qualitative data and methods was an alternative both to theoretical Marxism and positivism.

When qualitative research methods made their breakthrough, the everyday world was seen as problematic and interesting, and a series of studies were carried out on the way people really lived. Among the most popular study objects were suburbs in big cities and people who were the first generation residents there. We have in Finland a 
couple of remarkable examples of studies concentrating on the transformation of gender roles of women and men especially, when the mode of production changed in families after moving to cities from agrarian areas. It was shown how important work and everyday living conditions were when men constructed their masculine identity and what happened when the foundations of that identity were changed after moving to cities (Kortteinen 1982).

In the late 1970's and early 1980's researchers using qualitative approach all seemed to face challenges which looked as if they were personal and unique. Besides indepth interviews on everyday life, in the social sciences we had examples of semiotic studies of culture, anthropology, psychoanalytic studies using qualitative data and participative strategies. But there was no specific paradigm of qualitative research - unless the naturalistic or realistic attitude towards data is thought as one. Everyone had to find his or her own solutions to methodological problems. Usually, the data were gathered through interviews, and the problem of data distortion when interviewing was solved by triangulating them by other sources of data or using humanistic methods. By this I mean that researchers spent a lot of time with the people who were studied. Becoming almost a friend with them was thought to guarantee the truthfulness of the data. Friends do not betray or pretend, as we know...

\section{Process of establishment}

The late 1970's were in many ways a very successful period which saw the establishment of using qualitative methods in social sciences in Finland. It can be summarised into three different stages of discussion, or discourse, which can be found in other countries, too (Kvale 1989, Eskola \& Suoranta 1998). The first one - which still continues in some countries - was the legitimisation discourse which concentrated on questions like "Are there research questions that allow or even demand using qualitative methods?" - or "Can research based on qualitative data be scientific at all?" This discourse died down at least 15 years ago. Social scientists no longer quarrel about this. Qualitative and quantitative data and methods are seen equally valuable and important in the studies on social life.

The second discourse is a bit more complicated and it is still going on. Since it concerns the nature of research findings in social sciences it can be said to belong to philosophy of science. This discussion or battle, which followed soon after the first studies, focused on data as a text to be analysed and not as unproblematic information about the world under inspection. To put it simply, it can be described as a battle between relativism and objectivism, or perhaps as a battle between researchers who concentrate on culture and those who concentrate on structure. The third way to put it is to say that it is a discussion between social constructionism and realism. Constructionists are accused of concentrating on texts instead of important and real societal questions. Those who consider interviews as a source of information on the world being studied - i.e. realists - are accused of being unproblematic romanticists.

The third stage in this establishment process has been going on for years too. This discourse concentrates on the foundations of qualitative methods of analysis. This debate is going on mainly among researchers using qualitative methods. In this discourse researchers do not concentrate on questions like "is qualitative research science at all?" etc. It is more important is to improve the conduct of studies. That means developing and elaborating background theories, analysing principles, techniques etc.

Today, qualitative methods have a remarkably established position in the Finnish social sciences. For instance, if you come to study social sciences at the University of Tampere, the home of the FSD, you have to take a compulsory course not only in quantitative methods but also one in qualitative methods. In the academic year 2000-2001, first year students will have an introduction course on such areas as theory of rhetoric, narratology, action research, discourse analysis, conversation analysis and ethnography. In doctoral studies of sociology, the majority of the method courses concentrate on qualitative methods. Taking a look at all the method courses available you may even say that in social sciences qualitative methods constitute the mainstream in Finland.

This peculiar state of methodological affairs in Finland is one important reason why the Finnish Social Science Data Archive also focuses on information services for qualitative research. The FSD is planning to develop, together with other actors, a nation-wide net resource to support method teaching in social sciences as a practical example of adapting to the situation. It will facilitate, especially, the use of quantitative methods and research materials in academic teaching, but it will also contain material on teaching and using qualitative methods. Already we have a couple of excellent examples of combining quantitative and qualitative methods in doctoral theses, and more are on the way. We suppose that combining methods will become much more common in the future and that this will also mean changes in the demands for social science data archives.

\section{Perspectives and problems of archiving qualitative data in Finland}

In spite of having an established position in qualitative research and also a broad and continuously broadening spectrum of Finnish method books, we do not have any traditions of sharing, reusing, let alone archiving qualitative data. When thinking of the amount of research that has already been carried out and of the research projects which are going on these days in Finland, there is a huge waste of qualitative research resources. We have not done any surveys or interviews on questions of sharing and reusing 
qualitative data, but, judging by informal conversations, there is no doubt that researchers find it not only interesting but also very important.

The application of qualitative research methods defines our official strategy at the Finnish Social Science Data Archive: to promote reuse and documentation of qualitative data. The Archive plans to develop and maintain a database, of available qualitative data, which can be reused. It seems that there are quite a few practical problems though. First of all, until recently we did not have any official fixed storage facilities for qualitative data in Finland. This means that researchers have stored their data (if they still have their data) in their offices, or perhaps at home, maybe in the attic of their house; or maybe they have ended up taking it to their summer cottage where there seems to be space enough for things not needed anymore. Luckily we are living in the era of cd-players so the old tapes are not anymore in danger of being recorded over by contemporary pop music. Our own archive - the FSD - is meant for storing numerical and electronic data and there is not room for papers, cassettes, videotapes or anything which would need a lot of space.

Besides not having storage facilities, we do not have common principles of collecting, organising, indexing and documenting qualitative data; or to be more precise, principles vary according to university, discipline, research project, or sometimes even according to the researcher. That does not mean that researchers would not be strict and careful when doing research. We just have many different ways of being thorough and careful. For instance, researchers have their personal ways of indexing recorded videotapes. One of our duties is to develop, set, and propagate principles of collecting, documenting and organising qualitative data so that the data can be used by other researchers afterwards. When establishing documentation principles of qualitative data, we have to consider applying common principles to storing of qualitative data in universities, or specially designated archives, under the guidance of the National Archive, to alleviate researchers of the responsibility for finding a location for research material which is not used anymore.

When discussing possible archiving in the future, one problem which most of the researchers mention is the question of confidentiality and informed consent. This is perhaps one of the most important questions irrespective of the country in question. In connection with interviews, Finnish researchers do not usually use written informed consent which would be signed by the persons under study, but they often do promise not to disseminate the data, and that is as binding as a written contract. Questions of confidentiality and informed consent need also common principles; even though, there will always be some kinds of qualitative data which are not possible to reuse due to their delicate nature. The policies and principles of confidentiality will be settled in co-operation with university researchers and with several authorities responsible for these issues. These consultations will be the basis for setting rules of access and undertaking conditions of reuse of qualitative research material. We need to have common principles - perhaps as recommendations - of collecting, processing, organising and documenting qualitative data in a way that would enable a reuse of the data. To succeed in this we need also to co-operate with the main research funding organisations.

In the future we hope to be the advising partner in negotiations over the undertakings for conditions of reuse of qualitative material, even though the responsibility for the decision of granting access to the data lies with the principal investigators who have the kind of data which can be reused. The FSD will document but not store qualitative data unless it is in electronic form and without problems in view of matters related with confidentiality. It is our duty, however, to make recommendations for depositing or storing policies in the university departments. As a data archive we think it is a matter of course to catalogue also qualitative data which can be reused and inform about it through the internet and perhaps other media, too regardless of where the data is actually stored.

Finnish researchers are interested in the reuse of qualitative data, although the idea of organising and documenting their own data for reuse by someone else is not very interesting and tempting to them. Without common principles of collecting and documenting qualitative data, it might be that at times the burden of resources needed to make old material available for others outweighs the benefits of potential re-use. We can certainly start by trying to get some of the most significant qualitative material created in the past couple of decades; but realistically, the real potential of collecting qualitative data which would be available for others, lies in the current and future research projects. If we succeed in our work, there will be common principles for indexing and documenting qualitative material as well as guidelines for phrasing the introductory sections of interviews so that other researchers could use them, too. For the process of documenting and cataloguing qualitative data, we plan to be able to use some of the information elements which are already used in the new data documentation standards. In addition, we may have to develop some new information elements and elaborate some of the existing ones to meet the special requirements of qualitative data. It would be excellent if the objective of documentation of qualitative data would be achieved through co-operation between different archives.

In the future - perhaps even now - the Internet can be seen as a media for moving and exchanging both qualitative and quantitative material. A lot of qualitative material is already in machine-readable form. Knowing the possibilities of image scanning and digitising technologies, one can only 
imagine the future prospects and possibilities of archiving qualitative data. This vision and its actualisation can only contribute to the main task of data archives: enhancing sensible use of all research resources.

\section{References:}

Eskola, Jari and Suoranta, Juha: Johdatus laadulliseen tutkimukseen. Introduction to qualitative research. Vastapaino, Tampere 1998.

Kortteinen, Matti: Lähiö - tutkimus elämäntapojen muutoksesta. Suburb - a study on the change of lifestyle. Otava, Helsinki 1982.

Kvale, Steinar: Introduction. In Kvale, Steinar (ed.): Issues of Validity in qualitative research. Studentlitteratur, Lund 1989, pp 7-12.

Leskinen, Jaakko: Lyhyt katsaus suomalaiseen metodologiseen kirjallisuuteen. A short overview of Finnish methodological literature. In Leskinen, Jaakko (ed.): Laadullisen tutkimuksen risteysasemalla. In the cross-roads of qualitative research.

Kuluttajatutkimuskeskus, Helsinki 1995.

Waris, Heikki: Työläisyhdyskunnan syntyminen Helsingin Pitkänsillan pohjoispuolelle. Birth of a workers' community. Suomen Historiallinen Seura, Helsinki 1932.

Töttö, Pertti: Pirullinen positivismi. Kysymyksiä laadulliselle tutkimukselle. Diabolical positivism. Questions for qualitative research. Kampus Kustannus 41. Jyväskylä 1997.

* Paper presented at the IASSIST Conference, June 9, 2000, Northwestern University, Evanston, Chigago.

Arja Kuula is a Research Officer at the Finnish Social Science Data Archive. She has worked as a researcher at the Work Research Centre and at the Department of Sociology and Social Psychology at the University of Tampere. She has published articles and a book on methodological issues and the role of a researcher in research and development projects. Her areas of interest are qualitative data, research culture and methods. Her doctoral thesis in sociology deals with methodological issues of action research. 